\title{
Isolated thoracoschisis: Case report
}

\author{
Burak Ardıçl11 ${ }^{1}$, Ayşe Karaman ${ }^{1}$, Ahmet Özyazıc1 ${ }^{2}$, Ayşegül Zenciroğlu² ${ }^{2}$ Nurullah Okumuş² \\ ${ }^{1}$ Department of Pediatric Surgery and ${ }^{2}$ Division of Neonatology, Department of Pediatrics, Dr. Sami Ulus Maternity and \\ Children's Training and Research Hospital, Ankara, Turkey. \\ E-mail: burakardicli@gmail.com \\ Received: 8th February 2016, Revised: 17th February 2016, Accepted: 28th March 2016
}

SUMMARY: Ardıçlı B, Karaman A, Özyazıcı A, Zenciroğlu A, Okumuş N. Isolated thoracoschisis: Case report. Turk J Pediatr 2017; 59: 217-220.

Thoracoschisis is a rare congenital anomaly that refers to a congenital fissure of the chest wall. It is frequently accompanied with other congenital defects of the limbs and the abdominal wall as part of the limb-body wall complex, which is exencephaly/encephalocele and facial clefts, thoracoschisis and/or abdominoschisis and limb defects. Isolated thoracoschisis is a rare entity. We present a case of isolated thoracoschisis. A 24-week gestational age boy presented with a $3 \mathrm{~cm}$ chest wall defect in the left lateral $10^{\text {th }}$ intercostal space and intestines herniating through the defect. There was no history of maternal drug use during pregnancy. Birth weight was $500 \mathrm{~g}$. He underwent surgery. The intestines were reduced via the thoracic wall defect.

Key words: congenital defect, limb-body wall complex, thoracoschisis.

Thoracoschisis is a rare congenital anomaly characterized by evisceration of intraabdominal organs through a thoracic wall defect $^{1}$. Thoracoschisis resembles gastroschisis which is characterized by a defect on the anterior abdominal wall. However, the defect is on thoracic wall in the thoracoschisis. The etiology of this congenital anomaly is unknown. Thoracoschisis is frequently accompanied with other congenital anomalies of the limbs and the abdominal wall as part of the limb-body wall complex (LBWC) which is exencephaly/ encephalocele and facial clefts, thoracoschisis and/or abdominoschisis and limb defects ${ }^{2,3}$. Isolated thoracoschisis is a very rare condition. To the best of our knowledge; this is the $4^{\text {th }}$ case of isolated thoracoschisis reported in the English medical literature, which does not include evisceration of the liver.

\section{Case Report}

The patient was a male premature infant, with a gestational age of 24 -weeks, born to a 40-year-old mother by urgent Cesarean section due to preterm delivery. There was first cousin consanguinity between parents. There was no history of maternal drug use during pregnancy. Birth weight was $500 \mathrm{~g}$ and Apgar scores were 4 and 7 in $1^{\text {st }}$ and $5^{\text {th }}$ minutes, respectively. Prenatal follow-up was inadequate with no ultrasonographic examination. The patient was intubated, stabilized and then received surfactant (Curosurf ${ }^{\circledR}, 200 \mathrm{mg}$ / $\mathrm{kg}$ ) in the delivery room and was admitted to the neonatal intensive care unit. Physical examination revealed a $3 \mathrm{~cm}$ chest wall defect in the left lateral $10^{\text {th }}$ intercostal space and small intestines and colon eviscerating through the defect (Fig. 1). Transverse colon seemed ischemic. Intestines were wrapped with sterile wet hot gauze. Abdomen was scaphoid. Upper and lower extremities were normal and there were no other dysmorphic features. Postnatal echocardiography revealed patent ductus arteriosus and patent foramen ovale. Abdominal and chest X-ray demonstrated bilaterally normal diaphragm, gastric air on left upper quadrant and gas filled loops of intestine protruding from lateral side of left hemi thorax (Fig. 2). The patient underwent surgery on the third hour of his life. The intestines were reduced via the thoracic wall defect under general anesthesia. Abdominal cavity was explored through the defect and an additional incision was not necessary. Left hemi diaphragm was intact and there was not any abdominal visceral anomaly. After reduction of eviscerated intestines, transverse colon seemed 


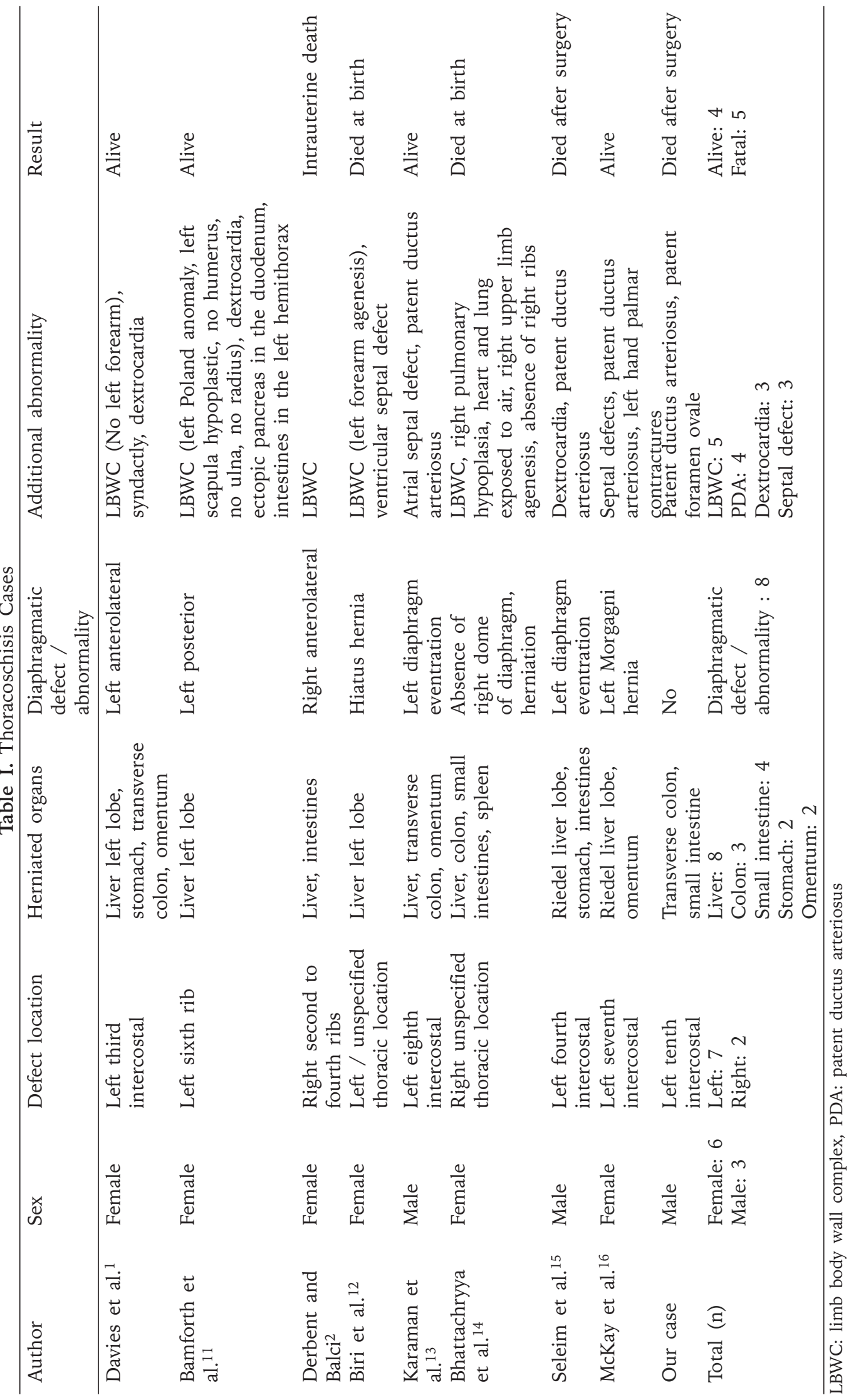




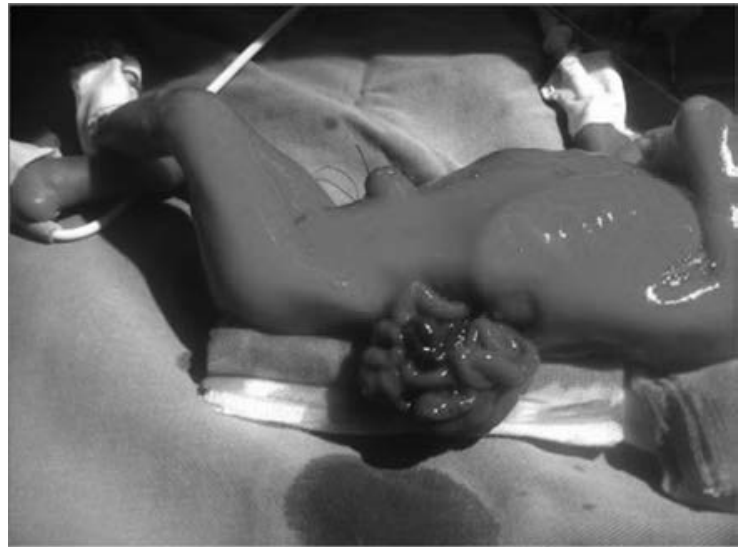

Fig. 1. The intestinal segments herniated through the thoracic defect. The circulation of the transverse colon was damaged.

better and there was no need for resection (Fig. 2). Postoperative X-ray demonstrated bilaterally normal hemi-diaphragms and normal intestinal gas distribution (Fig. 3). The patient died on the third postoperative day due to multi-organ failure. Autopsy and genetic evaluation was not possible since the parent did not give consent. The parent allowed the images and information to be used in the article.

\section{Discussion}

Thoracoschisis is a congenital anomaly, which is frequently accompanied with congenital defects of the limbs and the abdominal wall as part of the limb-body wall complex. The diagnostic criteria for LBWC is presence of at least two of the following three malformations; exencephaly/encephalocele and facial clefts, thoracoschisis and/or abdominoschisis and limb defects ${ }^{3}$.

Isolated thoracoschisis is a much rare entity defined with evisceration of intraabdominal organs through thoracic wall. Most of the isolated thoracoschisis cases reported have ipsilateral diaphragmatic hernia/eventration and all include evisceration of liver. Left sided thoracoschisis is most common and it is also predominant in females (Table $1)$. Our case is the first reported case of isolated thoracoschisis, which does not involve eviscerated liver, diaphragmatic abnormality and LBWC. Considering reported cases of LBWC and isolated thoracoschisis including a wide range of congenital defects, this rare clinical entity should be defined as a heterogeneous

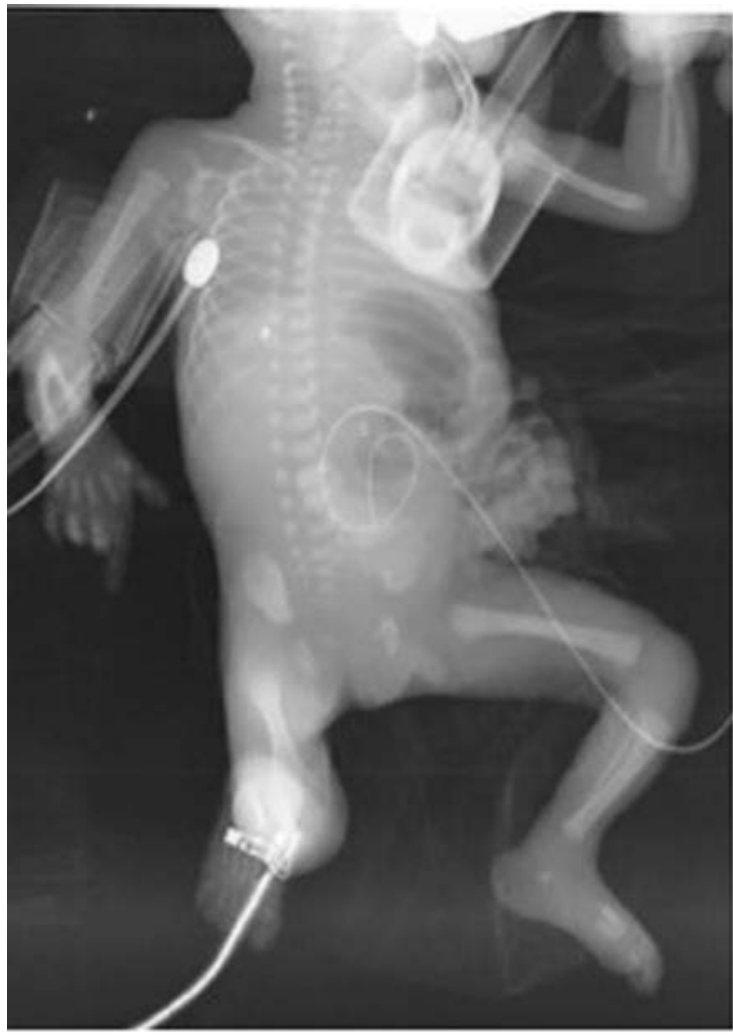

Fig. 2. Preoperative X-ray demonstrating normal diaphragm, gastric air on left upper quadrant and intestines protruding out.

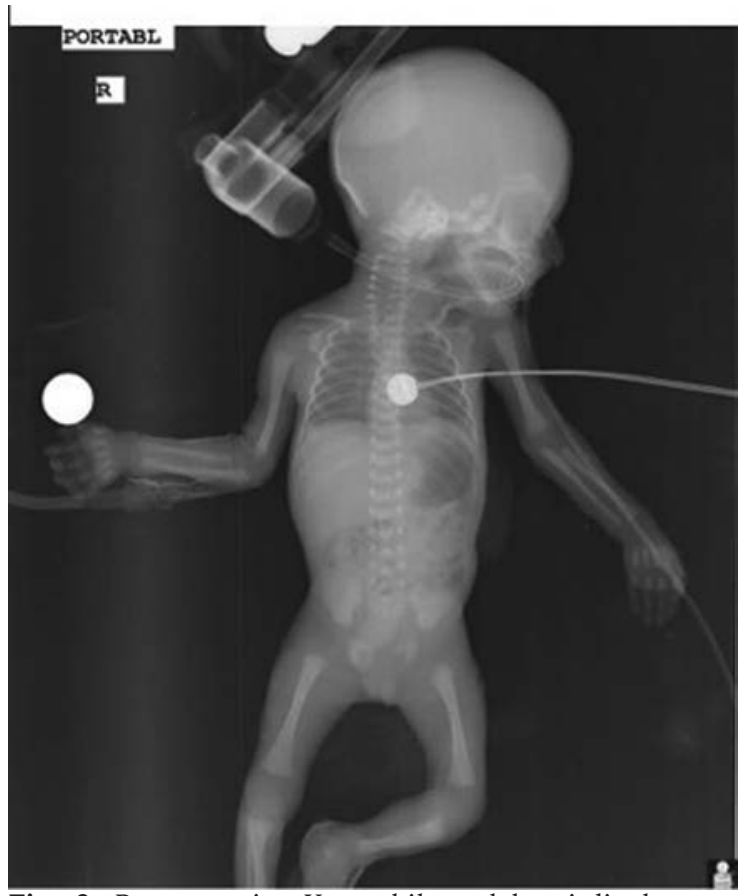

Fig. 3. Postoperative X-ray, bilateral hemi-diaphragms normal position and normal intestinal gas distribution. 
group of anomalies with different phenotypic occurrences. Previous classifications do not cover all cases reported ${ }^{4-7}$.

The etiology of this congenital anomaly is unknown. Theories on the pathogenesis of the LBWC are germ disc defect with early embryonic maldevelopment, primary rupture of the amnion leading to the formation of amniotic bands, vascular disruption and disturbance of the embryonic folding process ${ }^{1-3,8,9}$. Etiology has not been clearly associated with teratogenic agents and genetic abnormalities ${ }^{10}$.

Antenatal diagnosis is usually based on ultrasound examination. Prenatal magnetic resonance imaging demonstrates anatomic details defining the anomaly. Early diagnosis will allow appropriate management including termination of pregnancy according to the severity of congenital defects included. Eviscerated bowels should be wrapped with sterile wet gauze or sterile plastic bag in the delivery room to prevent heat and fluid loss and protect intestinal injury.

Survival depends on the extend of anomaly as well as gestational age of the newborn. Other reported cases ${ }^{1-7}$ in the literature without severe anomalies had chance of survival and survival seems to be higher in the cases with higher birth weight and older gestational age.

\section{REFERENCES}

1. Davies MR, Rode H, Cywes S. "Thoracoschisis" associated with an ipsilateral distal phocomelia and an anterolateral diaphragmatic hernia--a case report. J Pediatr Surg 1977; 12: 755-757.

2. Derbent M, Balci S. Thoracoschisis associated with diaphragmatic hernia in a 31-week-old stillbirth. Turk J Pediatr 2001; 43: 269-271.

3. Van Allen MI, Curry C, Gallagher L. Limb body wall complex: I. Pathogenesis. Am J Med Genet 1987; 28: 529-548.

4. Martinez-Frias ML. Clinical and epidemiological characteristics of infants with body wall complex with and without limb deficiency. Am J Med Genet 1997; 73: $170-175$.

5. Luebke HJ, Reiser CA, Pauli RM. Fetal disruptions: assessment of frequency, heterogeneity, and embryologic mechanisms in a population referred to a communitybased stillbirth assessment program. Am J Med Genet 1990; 36: 56-72.

6. Russo R, D'Armiento M, Angrisani P, Vecchione R. Limb body wall complex: a critical review and a nosological proposal. Am J Med Genet 1993; 47: 893-900.

7. Sahinoglu Z, Uludogan M, Arik $\mathrm{H}$, et al. Prenatal ultrasonographical features of limb body wall complex: a review of etiopathogenesis and a new classification. Fetal Pediatr Pathol 2007; 26: 135-151.

8. Higginbottom MC, Jones KL, Hall BD, Smith DW. The amniotic band disruption complex: timing of amniotic rupture and variable spectra of consequent defects. J Pediatr 1979; 95: 544-549.

9. Davies BR, Duran M. The confused identity of Cantrell's pentad: ectopia cordis is related either to thoracoschisis or to a diaphragmatic hernia with an omphalocele. Pediatr Pathol Mol Med 2003; 22: 383-390.

10. Pumberger W, Schaller A, Bernaschek G. Limb-body wall complex: a compound anomaly pattern in bodywall defects. Pediatr Surg Int 2001; 17: 486-490.

11. Bamforth JS, Fabian C, Machin G, et al. Poland anomaly with a limb body wall disruption defect: case report and review. Am J Med Genet 1992; 43: 780-784.

12. Biri A, Korucuoglu U, Turp A, Karaoguz M, Himmetoglu $\mathrm{O}$, Balci S. A new syndrome with prenatally diagnosed thoracoschisis, hiatal hernia and extremities' agenesis: case report. Genet Couns 2006; 17: 161-165.

13. Karaman I, Karaman A, Erdogan D, Cavusoglu YH, Ozguner IF. The first male with thoracoschisis: case report and review of the literature. J Pediatr Surg 2011; 46: 2181-2183.

14. Bhattacharyya NC, Gogoi M, Deuri PK. Thoracoschisis with limb agenesis. J Indian Assoc Pediatr Surg 2012; 17: 78-79.

15. Seleim HM, ElFiky MM, Fares AE, Elbarbary MM. Isolated thoracoschisis: Case report and review of literature. European J Pediatr Surg Rep 2015; 3: 40-42.

16. McKay JD, Parker CM, Loewen J, et al. Thoracoschisis: A case report and review of literature. Fetal Pediatr Pathol 2015; 34: 307-314. 